\title{
Glycopyrrolate/formoterol fumarate metered dose inhaler for maintenance- naïve patients with chronic obstructive pulmonary disease: a post-hoc analysis of the randomized PINNACLE trials
}

\author{
Jinping Zheng ${ }^{1 \dagger}$, Jin-fu Xu ${ }^{2 \dagger}$, Martin Jenkins ${ }^{3}$, Pryseley Nkouibert Assam ${ }^{4}$, Lijiao Wang ${ }^{5}$ and Brian J. Lipworth ${ }^{6 *}$ (D)
}

\begin{abstract}
Background: Glycopyrrolate (GP)/formoterol fumarate (FF; GFF) metered dose inhaler is a fixed-dose combination dual bronchodilator for patients with chronic obstructive pulmonary disease (COPD); however, whether the efficacy in patients without current maintenance treatment is consistent with currently maintenance-treated patients is unclear.

Methods: Data from patients who were not maintenance-treated at screening (NMT) ( $n=1943)$ and patients who were maintenance-treated at screening (MT) patients $(n=3040)$ receiving GFF, FF, GP, or placebo were pooled from the Phase III PINNACLE studies (NCT01854645, NCT01854658, NCT02343458) for post-hoc analysis. MT patients had received long-acting bronchodilators and/or inhaled corticosteroids in the 30 days prior to screening, and/or prior to randomization. NMT patients had received short-acting bronchodilators or no treatment. Outcomes included forced expiratory volume over $1 \mathrm{~s}\left(\mathrm{FEV}_{1}\right)$, clinically important deterioration (CID), rescue medication use, and safety.

Results: GFF provided significant lung function improvements at Week 24 versus placebo, GP, and FF for NMT patients, with pre-dose trough $\mathrm{FEV}_{1}$ treatment differences of $152(117-188) \mathrm{mL}, 73(45-100) \mathrm{mL}$, and $56(29-84) \mathrm{mL}$, respectively (least squares mean change from baseline versus comparators [95\% Cl]; all $P<0.0001$ ). GFF reduced the risk of CID by $17-43 \%$ in NMT $(P \leq 0.0157)$ and $18-52 \%(P \leq 0.0012)$ in MT patients compared with monotherapy and placebo, and reduced rescue medication use by 1.5 puffs/day over 24 weeks for both cohorts. Safety profiles for all cohorts were consistent with each other and the parent studies.

(Continued on next page)
\end{abstract}

\footnotetext{
* Correspondence: b.j.lipworth@dundee.ac.uk

This research is published as an abstract for the 24th Congress of the Asian

Pacific Society of Respirology; Hanoi, Vietnam, November 14-17, 2019.

Jinping Zheng and Jin-fu Xu are Co-primary authors.

${ }^{6}$ Scottish Centre for Respiratory Research, Ninewells Hospital, University of Dundee, Dundee DD1 9SY, Scotland, UK

Full list of author information is available at the end of the article
}

C C The Author(s). 2020 Open Access This article is licensed under a Creative Commons Attribution 4.0 International License, which permits use, sharing, adaptation, distribution and reproduction in any medium or format, as long as you give appropriate credit to the original author(s) and the source, provide a link to the Creative Commons licence, and indicate if changes were made. The images or other third party material in this article are included in the article's Creative Commons. licence, unless indicated otherwise in a credit line to the material. If material is not included in the article's Creative Commons licence and your intended use is not permitted by statutory regulation or exceeds the permitted use, you will need to obtain permission directly from the copyright holder. To view a copy of this licence, visit http://creativecommons.org/licenses/by/4.0/. The Creative Commons Public Domain Dedication waiver (http://creativecommons.org/publicdomain/zero/1.0/) applies to the data made available in this article, unless otherwise stated in a credit line to the data. 
(Continued from previous page)

Conclusions: NMT patients achieved better lung function with GFF versus monotherapy and placebo, without increased safety risk. Dual bronchodilator therapy may offer better outcomes than monotherapy for COPD patients when administered as first-line treatment.

Keywords: Glycopyrrolate/formoterol fumarate, Chronic obstructive pulmonary disease, Long-acting bronchodilator-naïve,

\section{Background}

Long-acting bronchodilators are recommended as firstline maintenance therapy for chronic obstructive pulmonary disease (COPD) to control symptoms and prevent exacerbations [1]. Currently, monotherapy with either a long-acting muscarinic antagonist (LAMA) or long-acting beta-agonist (LABA) is preferred, the exception being for stage $B$ patients as per the Global Initiative for Chronic Obstructive Lung Disease (GOLD B patients) who experience severe breathlessness, as well as highly symptomatic GOLD D patients. For these groups, LAMA/LABA or LABA/inhaled corticosteroid (ICS) combinations are indicated [1]. In patients with persistent dyspnea, exacerbations, or exercise limitations despite monotherapy, step-up treatment to a LAMA/ LABA combination is advised [1].

Limited evidence is available to guide the choice of first-line maintenance therapy in COPD [1]. Studies of maintenance treatment-naïve patients treated with monotherapy have found safety and efficacy outcomes to be consistent with unsorted populations, confirming that they are an appropriate first-line option [2-4]. However, many patients treated with monotherapy continue to experience COPD symptoms, exacerbations, and poor quality of life $[5,6]$. In randomized trials, LAMA/LABA combinations consistently provide superior lung function and exercise capacity improvements, and better symptom reduction than respective monocomponents [7-9]. A systematic review of LABA/LAMA versus LABA, LAMA, and LABA/ICS examined 27 studies to find significantly improved respiratory outcomes with dual LAMA/LABA therapy [9]. Commencing new patients directly on LAMA/LABA combinations may improve outcomes, irrespective of GOLD stage [10-12]. However, there is limited evidence clarifying whether dual therapy is appropriate for the initial treatment of COPD as few studies have been conducted in patients with lapsed or no prior history of maintenance therapy.

Glycopyrrolate/formoterol fumarate (GFF) metered dose inhaler (MDI) is a fixed-dose combination LAMA/ LABA bronchodilator administered in a single Aerosphere inhaler using innovative co-suspension delivery technology $[13,14]$. In the PINNACLE trials, GFF MDI achieved superior respiratory outcomes compared with monotherapy and placebo in patients with COPD across diverse treatment backgrounds [13, 14]. GFF MDI is currently approved for long-term COPD maintenance therapy in the USA, Europe, Canada, Australia, Japan, and South Korea, among others.

To assess whether GFF MDI is appropriate for initial maintenance treatment in COPD, we conducted a posthoc analysis comparing GFF to LAMA and LABA monocomponents and placebo in patients not receiving maintenance treatment at screening (NMT) and patients receiving maintenance treatment at screening (MT) pooled from three randomized phase III trials.

\section{Methods \\ Study design}

This study was a pooled, post-hoc analysis of three randomized, multicenter, international, double-blind, 24week Phase III clinical trials, PINNACLE-1 (NCT01854645), -2 (NCT01854658), and -4 (NCT02343458), which compared the efficacy of GFF MDI with its monocomponents and placebo. The study details and primary outcomes have previously been published $[13,14]$. Briefly, patients were randomized to receive twice-daily GFF MDI 14.4/9.6 $\mu$ g, glycopyrrolate (GP) MDI 14.4 $\mu \mathrm{g}$, formoterol fumarate (FF) MDI $9.6 \mu \mathrm{g}$, or placebo MDI. PINNACLE-1 included a tiotropium arm, which has been excluded from our analysis. Patients provided signed informed consent prior to screening. The studies were conducted in accordance with the amended Declaration of Helsinki and approved by local institutional review boards (details previously published) [13, 14].

\section{Participants}

Enrolled subjects were aged $>40$ years, from the USA, Australia, New Zealand, Europe, and Asia (including China and Japan), and current or former smokers $(\geq 10$ packs/year). They also had clinical history of moderateto-very severe COPD, defined per the American Thoracic Society/European Society criteria as patients with post-bronchodilator forced expiratory volume over $1 \mathrm{~s}$ $\left(\mathrm{FEV}_{1}\right) /$ forced vital capacity ratio $<0.70$, and $\mathrm{FEV}_{1}<80 \%$ predicted. Subjects were retrospectively classified by treatment history. MT patients were those who received any maintenance therapy (ICS, LAMA, LABA, or combinations) during the 30 days prior to screening or prior to 
randomization. NMT patients had received short-acting bronchodilators or remained untreated.

\section{Outcomes and procedures}

Lung function was assessed by change from baseline in morning pre-dose trough $\mathrm{FEV}_{1}$ at Week 24, a primary endpoint of all three parent studies. Peak change from baseline in $\mathrm{FEV}_{1}$ within $2 \mathrm{~h}$ post-dosing at Week 24 was a secondary endpoint. Spirometry was performed in accordance with the American Thoracic Society criteria. Other secondary endpoints included time to first clinically important deterioration (CID), health-related quality of life as assessed by St George's Respiratory Questionnaire (SGRQ), and symptom burden as assessed by rescue salbutamol use over 24 weeks. First CID was defined as the first occurrence of either $\geq 100 \mathrm{~mL}$ decline in trough $\mathrm{FEV}_{1}$, treatment-emergent moderate or severe COPD exacerbation, or increase of $\geq 4.0$ units on the SGRQ. Safety was assessed by adverse event monitoring. Subgroup analyses were performed for the NMT cohort in patients who were Chinese and patients who were symptomatic (baseline COPD Assessment Test [CAT] score $\geq 15)$.

\section{Statistical analysis}

Separate efficacy analyses were conducted within the NMT and MT groups. Patients were drawn from the intent-to-treat (ITT) populations of the parent trials, defined as subjects who were randomized and received $\geq 1$ dose of treatment (excluding tiotropium). Safety assessments utilised the safety population of the parent trials. Change from baseline in trough $\mathrm{FEV}_{1}$ was analyzed using a repeated measures linear model that included baseline and reversibility to salbutamol as continuous covariates, and study, treatment, visit, and treatment by visit interaction as categorical covariates. Similar repeated measures models were used for analyzing peak $\mathrm{FEV}_{1}, \mathrm{SGRQ}$, and salbutamol use. Time to first CID was analyzed using a Cox regression model adjusted for baseline percentage-predicted $\mathrm{FEV}_{1}$, baseline CAT score, baseline eosinophil count, study, exacerbation history in the previous year, smoking status, and baseline ICS use. For all analyses, pairwise treatment effect estimates were produced with $95 \%$ confidence intervals $(\mathrm{CIs})$ and $P$ values. These analyses were defined post-hoc, thus no adjustment for multiplicity was made, and they were not prospectively powered. $P$-values should be regarded as exploratory, and interpreted in terms of nominal significance.

\section{Results}

The pooled ITT population consisted of 4983 patients (GFF MDI, $n=1585$; FF MDI, $n=1360$; GP MDI, $n=$ 1362; placebo MDI, $n=676$ ), all of whom were included for efficacy analyses. Patients were classified as NMT $(n=1943)$ or MT $(n=3040)$ (Table 1$)$. Of the NMT patients $10.0 \%$ were Chinese and $64.7 \%$ were symptomatic. Similar demographics and baseline characteristics were broadly observed between the NMT and MT cohorts, and all treatment subgroups (Table 1; individual treatment groups not shown). There was a higher proportion of current smokers and subjects with moderate-severity COPD in the NMT cohort, compared to the MT cohort. Not unexpectedly, MT patients had longer treatment duration, and were more likely to be GOLD D stage than NMT patients.

Treatment with GFF MDI provided significant lung function improvements at Week 24 versus placebo, FF, and GP for NMT patients, with change from baseline

Table 1 Demographics and baseline characteristics

\begin{tabular}{|c|c|c|}
\hline & $\begin{array}{l}\text { NMT } \\
(\boldsymbol{n}=1943)\end{array}$ & $\begin{array}{l}\text { MT } \\
(\boldsymbol{n}=3040)\end{array}$ \\
\hline Age, mean (SD), years & $61.3(8.2)$ & $64.6(7.8)$ \\
\hline \multicolumn{3}{|l|}{ Sex, n (\%) } \\
\hline Male & $1193(61.4)$ & $1893(62.3)$ \\
\hline \multicolumn{3}{|l|}{ Race, n (\%) } \\
\hline White & $1563(80.4)$ & $2381(78.3)$ \\
\hline Asian & $229(11.8)$ & $482(15.9)$ \\
\hline Black or African American & $139(7.2)$ & $163(5.4)$ \\
\hline Other & $12(0.6)$ & $14(0.4)$ \\
\hline \multicolumn{3}{|l|}{ Smoking status } \\
\hline Current, n (\%) & $1244(64.0)$ & $1284(42.2)$ \\
\hline Former, n (\%) & $699(36.0)$ & $1756(57.8)$ \\
\hline Number of packs/year smoked, mean (SD) & $49.5(25.9)$ & $49.1(26.2)$ \\
\hline \multicolumn{3}{|l|}{ CAT score } \\
\hline Total CAT score, mean (SD) & $17.8(7.7)$ & $17.0(7.4)$ \\
\hline Symptomatic (CAT $\geq 15), \mathrm{n}(\%)$ & $1257(64.7)$ & $1825(60.0)$ \\
\hline mMRC grade, mean (SD) & $1.7(1.0)$ & $1.8(0.9)$ \\
\hline \multicolumn{3}{|l|}{ COPD severity, n (\%) } \\
\hline Mild (GOLD 1) & $13(0.7)$ & $17(0.6)$ \\
\hline Moderate (GOLD 2) & $1230(63.3)$ & $1534(50.5)$ \\
\hline Severe (GOLD 3) & $644(33.1)$ & $1327(43.7)$ \\
\hline Very severe (GOLD 4) & $56(2.9)$ & $162(5.3)$ \\
\hline \multicolumn{3}{|l|}{ GOLD 2017 category, n (\%) } \\
\hline A & $276(14.2)$ & $453(14.9)$ \\
\hline B & $1516(78.0)$ & $2177(71.6)$ \\
\hline C & $19(1.0)$ & $54(1.8)$ \\
\hline $\mathrm{D}$ & $125(6.4)$ & $348(11.4)$ \\
\hline Missing & $7(0.4)$ & $8(0.3)$ \\
\hline COPD duration, mean (SD), years & $6.5(6.3)$ & $7.6(6.2)$ \\
\hline
\end{tabular}

CAT COPD Assessment Test, COPD Chronic obstructive pulmonary disease, GOLD Global Initiative for Chronic Obstructive Lung Disease, mMRC Modified Medical Research Council scale, SD Standard deviation 
treatment differences in morning pre-dose trough $\mathrm{FEV}_{1}$ of $152 \mathrm{~mL}, 56 \mathrm{~mL}$, and $73 \mathrm{~mL}$, respectively (all $P<$ 0.0001) (Fig. 1a). The MT cohort had similar improvements with GFF versus placebo, FF, and GP (treatment differences of $140 \mathrm{~mL}, 71 \mathrm{~mL}$, and $49 \mathrm{~mL}$, respectively; all $P<0.0001$ ) (Fig. 1b). Significant differences between GFF and all comparators were observed as early as Week 2 and maintained over 24 weeks. Similar improvements were observed with GFF versus placebo, FF, and GP for peak change from baseline in $\mathrm{FEV}_{1}$ within $2 \mathrm{~h}$ post-dose at Week 24 (treatment differences for NMT: $283 \mathrm{~mL}, 79$ $\mathrm{mL}$, and $138 \mathrm{~mL}$, respectively; and MT: $291 \mathrm{~mL}, 109 \mathrm{~mL}$, and $133 \mathrm{~mL}$, respectively; all $P<0.0001$ ) (Fig. 1c-d). These findings were consistent with the overall ITT population.

GFF MDI improved CID measures for all patients. For NMT patients, GFF MDI reduced the risk of CID by 43, 21 , and $17 \%$ versus placebo, GP, and FF, respectively (Table 2). In the MT cohort, CID risk reduction with GFF MDI was 52,23 , and $18 \%$, respectively, as above. Median time to first CID, measured in weeks, was longer for GFF (20.1) versus placebo (12.1), GP (16.0), and FF
(16.1) for NMT patients (Fig. 2; Table 2). Increased time to first CID with GFF MDI was similarly observed in the MT cohort. Not unexpectedly, due to the higher proportion of GOLD D patients and with increased COPD severity, median time to CID was shorter in the MT cohort compared to NMT patients across all treatment groups.

GFF MDI reduced total SGRQ score from baseline by 4.397 and 4.126 points for NMT and MT patients at Week 24, respectively (Table 2). In the overall ITT population, more patients treated with GFF (40.8\%) achieved a minimal clinically important difference (MCID, defined as $\geq 4.0$ units of change from baseline) in SGRQ at Week 24 compared with FF (38.1\%), GP (35.0\%), and placebo (30.9\%). Rescue salbutamol use was reduced by 1.5 puffs/day over 24 weeks compared to baseline in subjects treated with GFF in both NMT and MT cohorts (Table 2), and was significantly reduced compared to placebo $(P<0.0001)$.

Symptomatic NMT patients treated with GFF MDI demonstrated improved lung function at Week 24, consistent with the overall NMT population. Change from

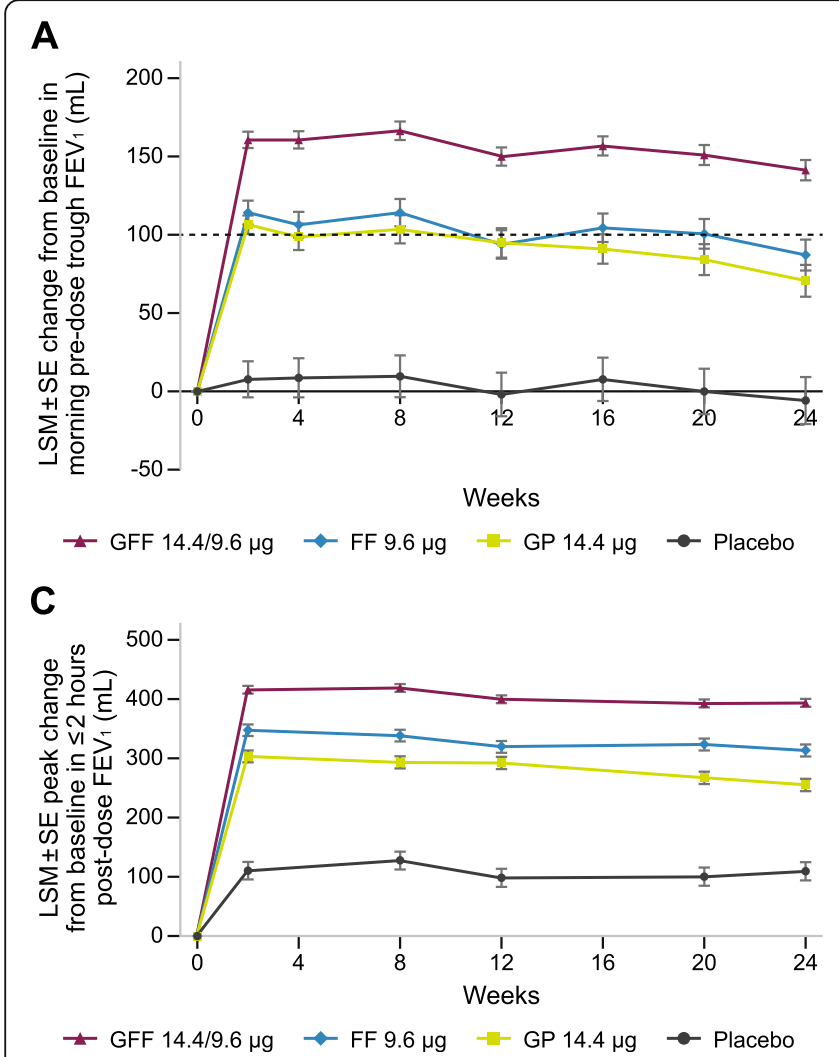

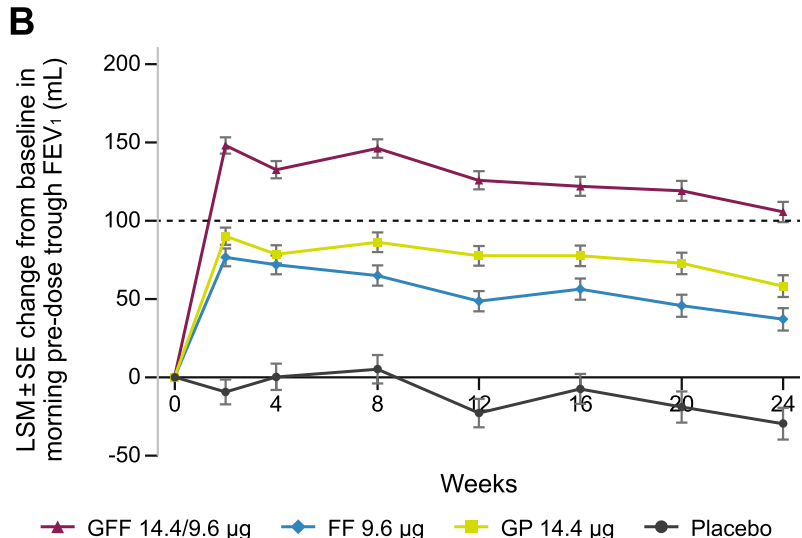

D

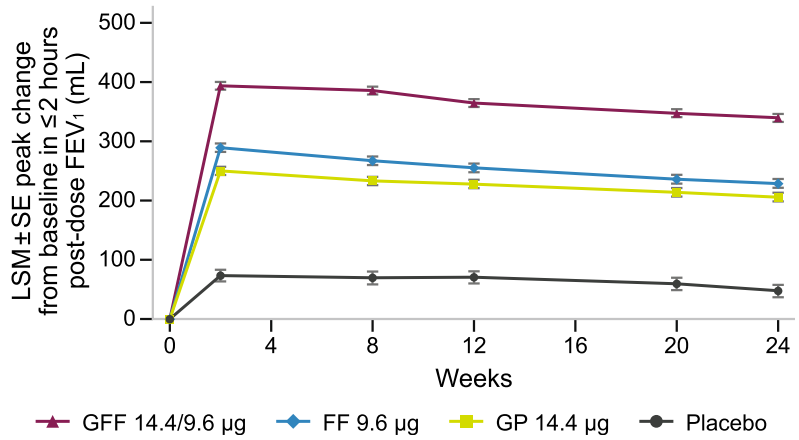

Fig. 1 Pre-dose trough and peak post-dose FEV for NMT (a, c) and MT (b, d) patients. $P<0.0001$ for all comparisons excluding FF versus GP. All $P$-values $<0.05$ should only be interpreted in terms of nominal significance as the analyses in these subgroups were exploratory and post-hoc. Interrupted line at $100 \mathrm{~mL}$ indicates $\mathrm{MCID}$ for change in trough $\mathrm{FEV}_{1}(1 \mathrm{~A}$ and $1 \mathrm{~B})$. COPD = chronic obstructive pulmonary disease; $\mathrm{FEV}_{1}=$ forced expiratory volume over $1 \mathrm{~s} ; \mathrm{FF}=$ formoterol fumarate; $\mathrm{GFF}=$ glycopyrrolate/formoterol fumarate; $\mathrm{GP}=$ glycopyrrolate; $\mathrm{LSM}=$ least squares mean; $M C I D=$ minimal clinically important difference; $M T$ = maintenance-treated at screening; $N M T=$ not maintenance-treated at screening; $\mathrm{SE}=$ standard error 


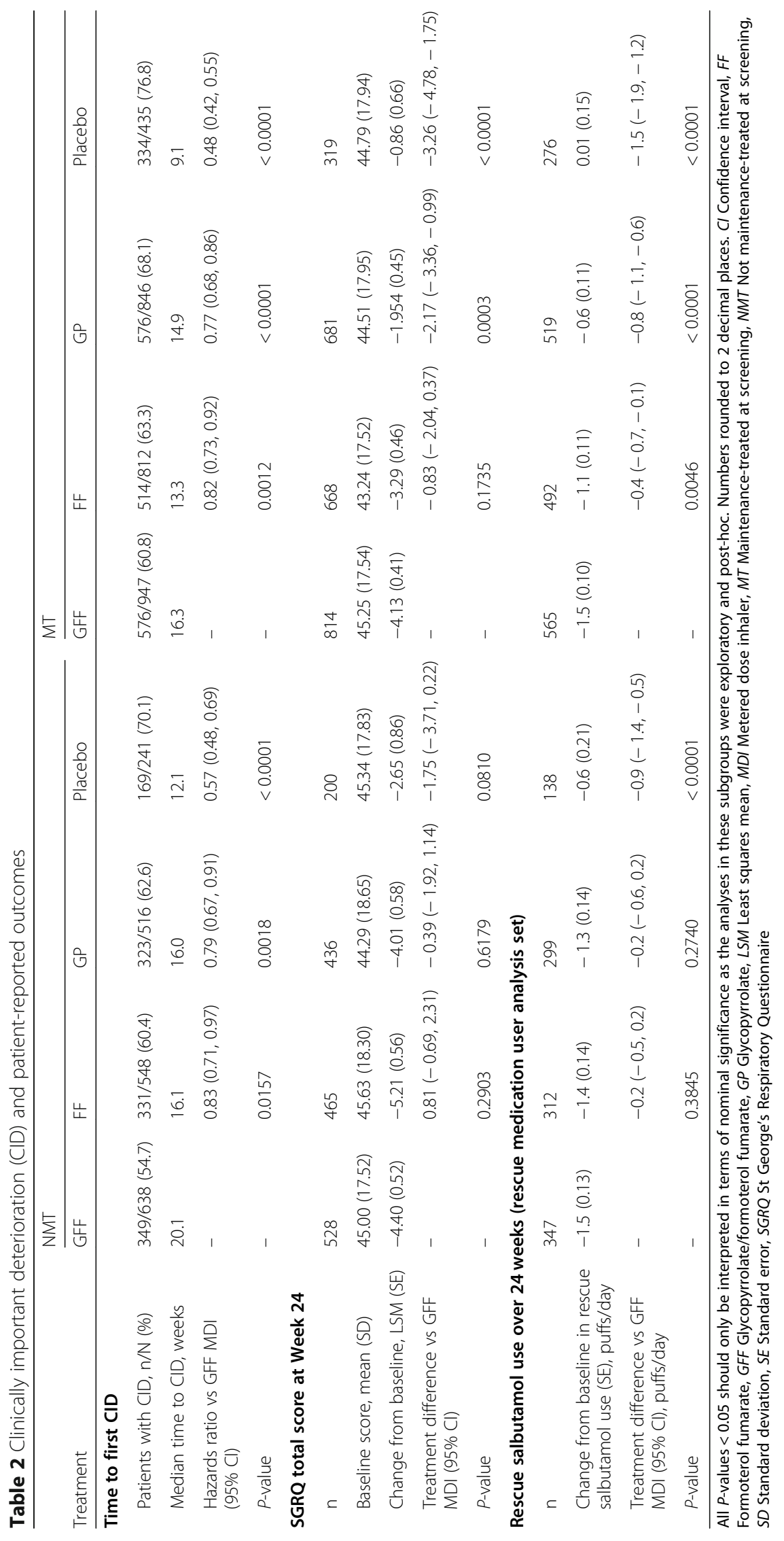




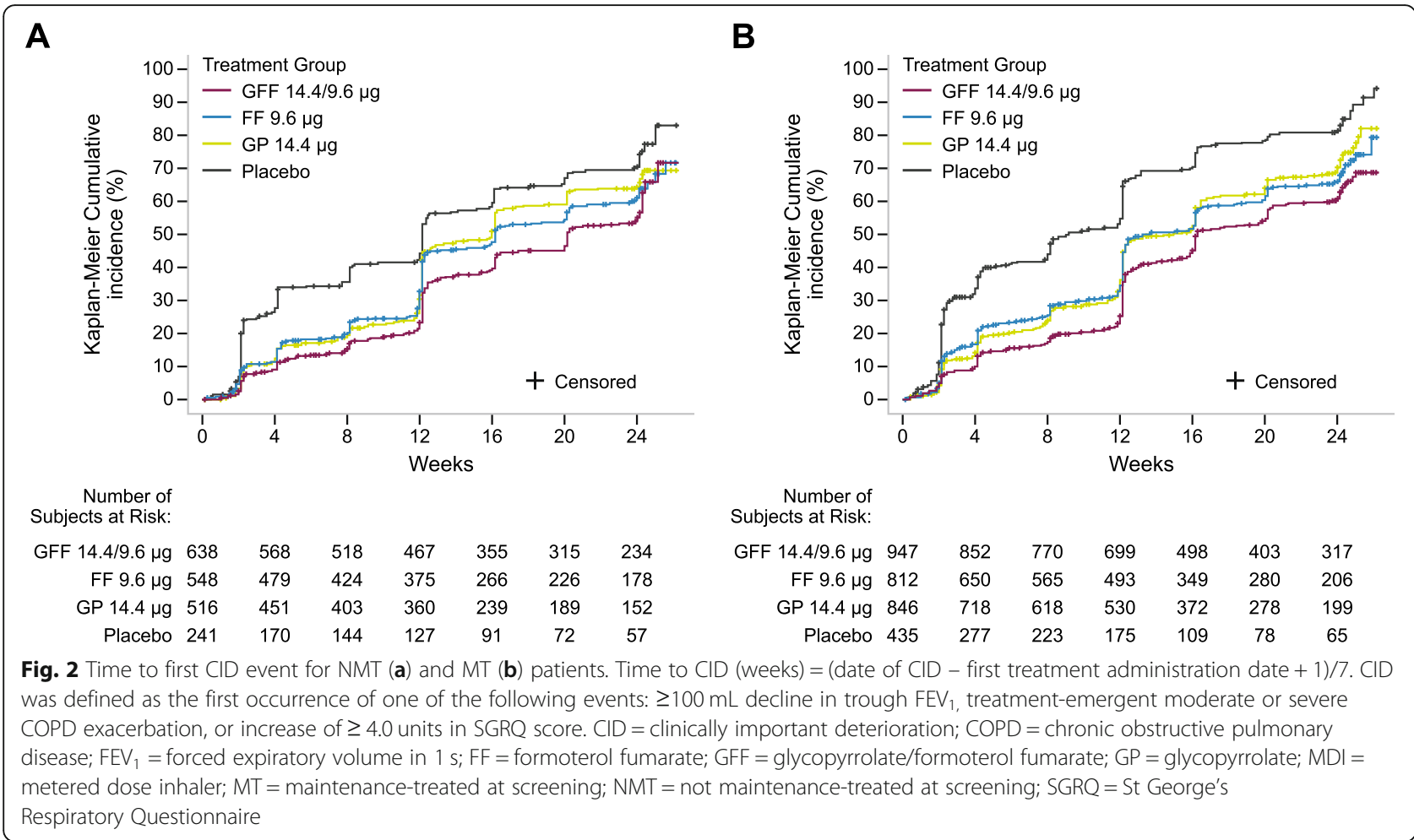

baseline in trough $\mathrm{FEV}_{1}$ was $126 \mathrm{~mL}$ with GFF MDI versus placebo $(P<0.0001), 49 \mathrm{~mL}$ versus FF $(P=0.0059)$, and $73 \mathrm{~mL}$ versus GP $(P<0.0001)$. For Chinese NMT patients, corresponding values for changes from baseline trough $\mathrm{FEV}_{1}$ were $175 \mathrm{~mL}(P=0.0008), 121 \mathrm{~mL}(P=$ $0.0017)$, and $103 \mathrm{~mL}(P=0.0065)$, respectively (Fig. 3a). GFF MDI also improved peak change from baseline in $\mathrm{FEV}_{1}$ in these subgroups; symptomatic NMT: $267 \mathrm{~mL}$ $(P<0.0001)$ versus placebo, $79 \mathrm{~mL}(P<0.0001)$ versus
FF, and $139 \mathrm{~mL}(P<0.0001)$ versus GP; Chinese NMT: $275 \mathrm{~mL}(P<0.0001)$ versus placebo, $160 \mathrm{~mL}(P=0.0005)$ versus FF, and $162 \mathrm{~mL}(P=0.0004)$ versus GP (Fig. 3b).

No new safety signals were identified from the pooled analysis. In total, 55.5 and $57.2 \%$ of patients experienced $\geq 1$ treatment-emergent adverse event (TEAE) in the NMT and MT cohorts, respectively, with the majority considered non-serious and unrelated to study treatment (Table 3). Treatment discontinuation following TEAEs
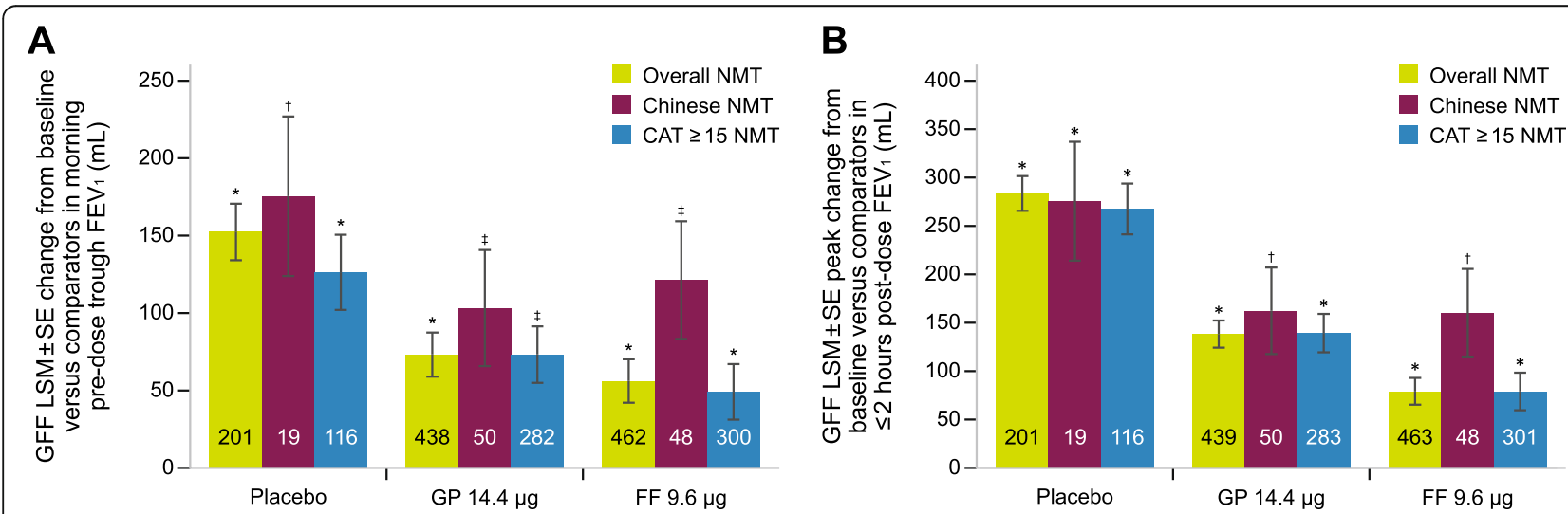

Fig. 3 Trough FEV ${ }_{1}(\mathbf{a})$ and peak post-dose FEV $(\mathbf{b})$ in Chinese and symptomatic NMT patients. Data labels within columns are $N$ number. * $P<$ $0.0001,{ }^{\dagger} P \leq 0.001$, and ${ }^{\ddagger} P \leq 0.01$, compared with GFF MDI. All P-values $<0.05$ should only be interpreted in terms of nominal significance as the analyses in these subgroups were exploratory and post-hoc. CAT = COPD Assessment Test; COPD = chronic obstructive pulmonary disease; $\mathrm{FEV}_{1}=$ forced expiratory volume in $1 \mathrm{~s} ; \mathrm{FF}=$ formoterol fumarate; GFF = glycopyrrolate/formoterol fumarate; GP = glycopyrrolate; $\mathrm{LSM}=$ least squares mean; $\mathrm{MDI}=$ metered dose inhaler; $\mathrm{NMT}=$ not maintenance-treated at screening; $\mathrm{SE}=$ standard error 
Table 3 Summary of adverse events

\begin{tabular}{|c|c|c|c|c|c|c|c|c|}
\hline \multirow[b]{2}{*}{ Treatment } & \multicolumn{4}{|l|}{ NMT } & \multicolumn{4}{|l|}{ MT } \\
\hline & $\begin{array}{l}\text { GFF } \\
(\boldsymbol{n}=638)\end{array}$ & $\begin{array}{l}\mathrm{FF} \\
(\boldsymbol{n}=548)\end{array}$ & $\begin{array}{l}\text { GP } \\
(\boldsymbol{n}=516)\end{array}$ & $\begin{array}{l}\text { Placebo } \\
(\boldsymbol{n}=241)\end{array}$ & $\begin{array}{l}\text { GFF } \\
(\boldsymbol{n}=947)\end{array}$ & $\begin{array}{l}\text { FF } \\
(\boldsymbol{n}=812)\end{array}$ & $\begin{array}{l}\mathrm{GP} \\
(\boldsymbol{n}=846)\end{array}$ & $\begin{array}{l}\text { Placebo } \\
(\boldsymbol{n}=435)\end{array}$ \\
\hline \multicolumn{9}{|l|}{ TEAEs, n (\%) } \\
\hline Patients with $\geq 1$ TEAE & $362(56.7)$ & $304(55.5)$ & $280(54.3)$ & $133(55.2)$ & $560(59.1)$ & $457(56.3)$ & $469(55.4)$ & $252(57.9)$ \\
\hline Patients with serious TEAEs & $43(6.7)$ & $33(6.0)$ & $35(6.8)$ & $18(7.5)$ & $90(9.5)$ & $73(9.0)$ & $72(8.5)$ & $32(7.4)$ \\
\hline Deaths (all-cause) during treatment period & $1(0.2)$ & $1(0.2)$ & $0(0)$ & $1(0.4)$ & $4(0.4)$ & $1(0.1)$ & $1(0.1)$ & $1(0.2)$ \\
\hline \multicolumn{9}{|l|}{ TRAEs, n (\%) } \\
\hline Patients with TEAEs related to study treatment & $75(11.8)$ & $58(10.6)$ & $51(9.9)$ & $19(7.9)$ & $97(10.2)$ & $86(10.6)$ & $99(11.7)$ & $50(11.5)$ \\
\hline Patients with serious TEAEs related to study treatment & $7(1.1)$ & $1(0.2)$ & $6(1.2)$ & $1(0.4)$ & $3(0.3)$ & $7(0.9)$ & $9(1.1)$ & $2(0.5)$ \\
\hline \multicolumn{9}{|l|}{ Common TEAEs, n (\%) } \\
\hline Upper respiratory tract infection & $28(4.4)$ & $20(3.6)$ & $26(5.0)$ & $13(5.4)$ & $42(4.4)$ & $39(4.8)$ & $41(4.8)$ & $29(6.7)$ \\
\hline Viral upper respiratory tract infection & $31(4.9)$ & $28(5.1)$ & $20(3.9)$ & $10(4.1)$ & $44(4.6)$ & $43(5.3)$ & $41(4.8)$ & $16(3.7)$ \\
\hline Dyspnea & $11(1.7)$ & $8(1.5)$ & $7(1.4)$ & $7(2.9)$ & $24(2.5)$ & $27(3.3)$ & $25(3.0)$ & $19(4.4)$ \\
\hline Nasopharyngitis & $14(2.2)$ & $14(2.6)$ & $9(1.7)$ & $10(4.1)$ & $31(3.3)$ & $15(1.8)$ & $16(1.9)$ & $9(2.1)$ \\
\hline Back pain & $17(2.7)$ & $12(2.2)$ & $10(1.9)$ & $9(3.7)$ & $19(2.0)$ & $13(1.6)$ & $19(2.2)$ & $2(0.5)$ \\
\hline Cough & $23(3.6)$ & $11(2.0)$ & $14(2.7)$ & $6(2.5)$ & $31(3.3)$ & $21(2.6)$ & $23(2.7)$ & $8(1.8)$ \\
\hline COPD & $14(2.2)$ & $11(2.0)$ & $16(3.1)$ & $5(2.1)$ & $26(2.7)$ & $19(2.3)$ & $26(3.1)$ & $15(3.4)$ \\
\hline Bronchitis & $9(1.4)$ & $5(0.9)$ & $9(1.7)$ & $2(0.8)$ & $15(1.6)$ & $13(1.6)$ & $26(3.1)$ & $15(3.4)$ \\
\hline Hypertension & $14(2.2)$ & $5(0.9)$ & $6(1.2)$ & $8(3.3)$ & $14(1.5)$ & $16(2.0)$ & $14(1.7)$ & $16(3.7)$ \\
\hline Headache & $15(2.4)$ & $17(3.1)$ & $11(2.1)$ & $3(1.2)$ & $15(1.6)$ & $18(2.2)$ & $20(2.4)$ & $4(0.9)$ \\
\hline
\end{tabular}

Common TEAEs defined as those occurring in $\geq 3 \%$ of patients in any treatment arm. COPD Chronic obstructive pulmonary disease, FF Formoterol fumarate, GFF Glycopyrrolate and formoterol fumarate, GP Glycopyrrolate, MT Maintenance-treated at screening, NMT Not maintenance-treated at screening, TEAE Treatmentemergent adverse event, TRAE Treatment-related adverse event

were limited, ranging from $4.6 \%$ (FF) to $5.5 \%$ (GFF) of NMT subjects, and $5.7 \%$ (FF) to $7.1 \%$ (placebo) of MT subjects. Three deaths occurred in the NMT cohort (one each in placebo, FF, and GFF subjects), and seven occurred in the MT cohort (one each in placebo, GP, and FF subjects, and four in GFF subjects) over the study period; none were considered treatment-related.

\section{Discussion}

This post-hoc analysis is the first to compare GFF MDI with its monocomponents in patients grouped by prior exposure to maintenance therapy. Long-acting dual bronchodilators are primarily recommended for step-up treatment following unsatisfactory disease control with first-line LABA or LAMA monotherapy. However, many patients indicated for monotherapy experience ongoing symptoms and respiratory decline during treatment $[1$, $5,6]$. Analyses examining whether patients may benefit from commencing LAMA/LABA therapy directly are emerging, but none have included GFF [15-20]. In our analysis, GFF MDI significantly improved respiratory outcomes for both NMT and MT cohorts compared with monocomponents and placebo, without increasing safety concerns. This suggests that GFF MDI may be used as first-line therapy, achieving similar safety and efficacy to current use. Improved stratification is needed to identify patients who may benefit from direct dual therapy, to avoid over-medication in those who could be managed sufficiently with a single LAMA or LABA.

In our analysis, GFF MDI provided greater improvement to morning pre-dose trough and post-dose peak $\mathrm{FEV}_{1}$ measures from baseline, compared with monocomponents and placebo in both NMT and MT subjects at Week 24 and over 24 weeks. GFF exceeded the MCID for morning pre-dose trough $\mathrm{FEV}_{1}$ in both cohorts [21]. These findings are consistent with previous primary analyses of the PINNACLE studies, and consistent for the symptomatic and Chinese NMT subgroups.

Currently, first-line LAMA/LABA combinations are only recommended for highly symptomatic subsets of GOLD B and D patients [1]. Unlike trials in some other LAMA/LABA fixed-dose combinations [17, 22], the PINNACLE studies were not restricted to symptomatic patients. A recent pooled analysis found that respiratory benefits for the total population were upheld in GOLD A PINNACLE patients, classified as those with CAT $<10$ /modified Medical Research Council scale of $0-1$, $\leq 1$ moderate exacerbation in the previous year, and no exacerbations leading to hospitalization in the previous year, suggesting GFF MDI is suitable for patients with milder symptoms and low exacerbation risk [23]. In our analysis, $14 \%$ of patients in the NMT and MT cohorts 
were classified as GOLD A. Hence, our findings support the safety and efficacy of first-line GFF MDI for patients with varying symptom burden.

CID is a composite measure of functional and patientreported outcomes, indicative of worsening COPD and linked to poor long-term outcomes [19]. GFF reduced the risk of CID by 17 and 21\% compared with FF and GP, respectively, and by $43 \%$ compared with placebo in NMT subjects, suggesting the combination more effectively stabilizes outcomes representative of disease progression. This trend was upheld in MT patients. SGRQ total score, which feeds into the CID outcome as a quality of life measure, was also improved by GFF MDI for both cohorts. CID improvements in NMT patients were not driven by exacerbation differences, as this group included predominately GOLD B patients who are at low exacerbation risk.

In our study, rescue salbutamol use was reduced by 1.5 puffs/day (approximately one-third of baseline puffs/ day) over 24 weeks in NMT and MT patients treated with GFF MDI. All comparators reduced salbutamol use compared with placebo. A recent systematic review of 46 studies found that changes in rescue medication use are associated with important COPD measures, including SGRQ score, dyspnea, exacerbation rate, and trough $\mathrm{FEV}_{1}$ [24].

No further safety findings emerged from the analysis. TEAEs and TEAE-related discontinuations were similar across all treatment groups and populations. These findings concur with other meta-analyses and systematic reviews, which continue to find no additional or synergistic safety signals when LAMAs and LABAs are used in combination $[25,26]$.

Preliminary analyses of other LAMA/LABA combinations demonstrate that first-line dual therapy may be more efficacious than monotherapy. Maximizing bronchodilation is a key outcome of maintenance therapy. Previous analyses of monotherapies in various maintenance treatment-naïve populations have found similar safety and efficacy results to unsorted populations [2-4]. To our knowledge, maintenance treatment-naïve populations have achieved greater respiratory improvements with dual bronchodilators over monotherapy in all studies to date. A pre-specified subgroup analysis of maintenance treatment-naïve and maintenance-treated patients treated with umeclidinium/vilanterol reported significant improvements in trough $\mathrm{FEV}_{1}$, reaching MCID in NMT patients [15]. Better respiratory improvements with dual bronchodilation were found for maintenance treatment-naïve patients in retrospective studies comparing umeclidinium/vilanterol to tiotropium, and tiotropium/olodaterol to tiotropium and placebo [16, 17]. Long-acting bronchodilator-naïve patients treated with indacaterol, glycopyrronium, or a combination also achieved optimal respiratory outcomes via a combination approach [18]. First-line dual bronchodilation has been shown to reduce exacerbation risk, dyspnea, risk of CID, and rescue medication use, whilst improving patient-reported symptom scores, health-related quality of life, and SGRQ scores [15-20, 27]. These data lend further support for the preferential use of combination treatments for first-line COPD maintenance therapy.

All but one [15] study in populations with lapsed or no prior history of maintenance treatment, including our own, have been designed post-hoc. These findings are hence provisional, and there remains a paucity of prospective data. Nonetheless, coupled with the understanding that effective maintenance therapy should be commenced promptly to prevent the increased rate of pulmonary decline observed in early disease [3, 28-33], these findings support the case for commencing COPD patients directly on LAMA/LABA to improve symptoms and preserve lung function.

Limitations of our study include that the PINNACLE trials were not prospectively powered with NMT and MT subgroups in mind. Prospective studies of first-line dual bronchodilator therapy are required. More targeted subgroups would also be of interest; future research should examine outcomes in patients who only briefly receive LABA or LAMA monotherapy prior to escalation, a common clinical occurrence, compared to those directly prescribed dual therapy. Similarly, future research should assess first-line dual LAMA/LABA treatment in real-world populations.

\section{Conclusions}

Our analysis found important efficacy advantages, with no safety, tolerability, or efficacy disadvantages to commencing GFF MDI in the NMT population. These data add to the growing body of evidence supporting LABA/ LAMA combination therapies for the first-line treatment of moderate-to-very severe COPD in appropriate patients. Validation of these findings with prospective and realworld studies are required.

\section{Abbreviations \\ CAT: COPD Assessment Test; Cl: Confidence interval; CID: Clinically important deterioration; COPD: Chronic obstructive pulmonary disease; FEV $\mathrm{F}_{1}$ : Forced expiratory volume over 1 s; FF: Formoterol fumarate; GFF: Glycopyrrolate/ formoterol fumarate; GOLD: Global Initiative for Chronic Obstructive Lung Disease; GP: Glycopyrrolate; ICS: Inhaled corticosteroid; ITT: Intent to treat; LABA: Long-acting beta-agonist; LAMA: Long-acting muscarinic antagonist; MCID: Minimal clinically important difference; MDI: Metered dose inhaler; MT: Maintenance-treated at screening; NMT: Not maintenance-treated at screening; SGRQ: St George's Respiratory Questionnaire; TEAE: Treatment- emergent adverse event}

\section{Acknowledgements}

Medical writing support, under the direction of the authors, was provided by Kristen Perry of Nucleus Global, Shanghai, China, funded by AstraZeneca in accordance with Good Publication Practice (GPP3) guidelines [34]. The authors would like to thank the patients and their families, staff members at 
all study sites, and investigators, pharmacists, and clinical research associates involved in the original studies.

\section{Authors' contributions}

JZ, JX, and LW conceived and designed the analysis. MJ designed and performed the statistical analyses. All authors were involved in data analysis, data interpretation, and preparation of the final manuscript. The authors read and approved the final manuscript.

\section{Funding}

This study was funded by AstraZeneca. The PINNACLE studies were supported by Pearl, a member of the AstraZeneca Group. The sponsor had access to the study data and reviewed and approved the manuscript for publication.

\section{Availability of data and materials}

Data underlying the findings described in this manuscript may be obtained in accordance with AstraZeneca's data sharing policy described at: https:// astrazenecagrouptrials.pharmacm.com/ST/Submission/Disclosure.

\section{Ethics approval and consent to participate}

The original PINNACLE-1, -2 , and - 4 studies were conducted in accordance with the amended Declaration of Helsinki and approved by local institutional review boards (details previously published) $[13,14]$. Patients provided signed informed consent prior to screening.

\section{Consent for publication}

Not applicable.

\section{Competing interests}

BJL declares research grants from AstraZeneca, Boehringer Ingelheim, Chiesi, and Janssen. BJL declares speaker fees from AstraZeneca, Boehringer Ingelheim, and Teva. BJL declares consulting fees from Boehringer Ingelheim, Chiesi, Sandoz, Cipla, Dr. Reddys, and Lupin. BJL declares advisory board fees from Teva. JZ declares advisory board fees from AstraZeneca, Boehringer Ingelheim and grants from GlaxoSmithKline. MJ, PNA, and LW are employees of AstraZeneca. MJ is a shareholder of AstraZeneca. The authors declare that they have no competing interests.

\section{Author details}

${ }^{1}$ State Key Laboratory of Respiratory Disease, National Clinical Research Center of Respiratory Disease, Guangzhou Institute of Respiratory Health, First Affiliated Hospital of Guangzhou Medical University, Guangzhou, China. 2Department of Respiratory and Critical Care Medicine, Shanghai Pulmonary Hospital, Tongji University School of Medicine, Shanghai, China. ${ }^{3} \mathrm{Global}$ Medicines Development, AstraZeneca, Central Cambridge, UK. ${ }^{4}$ Global Medicines Development, AstraZeneca, Shanghai, China. ${ }^{5}$ Medical Affairs, AstraZeneca, Shanghai, China. ${ }^{6}$ Scottish Centre for Respiratory Research, Ninewells Hospital, University of Dundee, Dundee DD1 9SY, Scotland, UK.

\section{Received: 22 December 2019 Accepted: 2 March 2020}

Published online: 12 March 2020

\section{References}

1. Global Initiative for Chronic Obstructive Lung Disease (GOLD). Global strategy for the diagnosis, management, and prevention of chronic obstructive pulmonary disease; 2019. https://goldcopd.org/gold-reports/. Accessed 27 Sep 2019.

2. Decramer M, Rossi A, Lawrence D, McBryan D. Indacaterol therapy in patients with COPD not receiving other maintenance treatment. Respir Med. 2012;106:1706-14.

3. Troosters T, Sciurba FC, Decramer M, Siafakas NM, Klioze SS, Sutradhar SC, et al. Tiotropium in patients with moderate COPD naive to maintenance therapy: a randomised placebo-controlled trial. NPJ Prim Care Respir Med. 2014;24:14003

4. Vogelmeier C, Fabbri LM, Rabe KF, Beeh KM, Schmidt H, Metzdorf N, et al. Effect of tiotropium vs. salmeterol on exacerbations: GOLD II and maintenance therapy naive patients. Respir Med. 2013;107:75-83.

5. Dransfield MT, Bailey W, Crater G, Emmett A, O'Dell DM, Yawn B. Disease severity and symptoms among patients receiving monotherapy for COPD. Prim Care Respir J. 2011;20:46-53.
6. Price D, West D, Brusselle G, Gruffydd-Jones K, Jones R, Miravitlles M, et al. Management of COPD in the UK primary-care setting: an analysis of real-life prescribing patterns. Int J Chron Obstruct Pulmon Dis. 2014;9:889-904.

7. Calzetta L, Ora J, Cavalli F, Rogliani P, O'Donnell DE, Cazzola M. Impact of $\angle A B A / L A M A$ combination on exercise endurance and lung hyperinflation in COPD: a pair-wise and network meta-analysis. Respir Med. 2017;129:189-98.

8. Calzetta L, Rogliani P, Matera MG, Cazzola M. A systematic review with meta-analysis of dual bronchodilation with LAMA/LABA for the treatment of stable COPD. Chest. 2016;149:1181-96.

9. Rogliani P, Calzetta L, Braido F, Cazzola M, Clini E, Pelaia G, et al. LABA/ LAMA fixed-dose combinations in patients with COPD: a systematic review. Int J Chron Obstruct Pulmon Dis. 2018;13:3115-30.

10. Barrecheguren M, Miravitlles M. COUNTERPOINT: should LAMA/LABA combination therapy be used as initial maintenance treatment for COPD? No. Chest. 2018:154:749-51.

11. Cazzola M, Matera MG. POINT: should LAMA/LABA combination therapy be used as initial maintenance treatment for COPD? Yes Chest. 2018;154(4): $746-8$.

12. Anzueto $A$, Miravitlles $M$. The role of fixed-dose dual bronchodilator therapy in treating COPD. Am J Med. 2018;131:608-22.

13. Lipworth BJ, Collier DJ, Gon Y, et al. Improved lung function and patientreported outcomes with co-suspension delivery technology glycopyrrolate/ formoterol fumarate metered dose inhaler in COPD: a randomized phase III study conducted in Asia, Europe, and the USA. Int J Chron Obstruct Pulmon Dis. 2018;13:2969-84.

14. Martinez FJ, Rabe KF, Ferguson GT, et al. Efficacy and safety of glycopyrrolate/ formoterol metered dose inhaler formulated using co-suspension delivery technology in patients with COPD. Chest. 2017;151:340-57.

15. Bjermer LH, Kerwin E, Maltais F, Jones P, Boucot I, Tombs L, et al. Comparative efficacy and safety of umeclidinium/vilanterol, umeclidinium and salmeterol in symptomatic maintenance-naïve and maintenance-treated chronic obstructive pulmonary disease: a pre-specified secondary analysis of the EMAX trial. Am J Respir Crit Care Med. 2019;199(Suppl 1):A3317.

16. Singh D, Gaga M, Schmidt O, Bjermer L, Gronke L, Voss F, et al. Effects of tiotropium + olodaterol versus tiotropium or placebo by COPD disease severity and previous treatment history in the OTEMTO(R) studies. Respir Res. 2016;17:73.

17. Maleki-Yazdi MR, Singh D, Anzueto A, Tombs L, Fahy WA, Naya I. Assessing short-term deterioration in maintenance-naive patients with COPD receiving umeclidinium/vilanterol and tiotropium: a pooled analysis of three randomized trials. Adv Ther. 2017;33:2188-99.

18. Muro S, Yoshisue H, Kostikas K, Olsson P, Gupta P, Wedzicha JA. Indacaterol/ glycopyrronium versus tiotropium or glycopyrronium in long-acting bronchodilator-naive COPD patients: a pooled analysis. Respirology. 2019. https://doi.org/10.1111/resp.13651.

19. Naya I, Tombs L, Lipson DA, Boucot I, Compton C. Impact of prior and concurrent medication on exacerbation risk with long-acting bronchodilators in chronic obstructive pulmonary disease: a post hoc analysis. Respir Res. 2019:20:60.

20. Alcázar Navarrete B, Boucot I, Naya I, Tombs L, Lipson DA, et al. Umeclidinium/vilanterol versus tiotropium/olodaterol in maintenance-naïve patients with moderate symptomatic chronic obstructive pulmonary disease: a post hoc analysis. Pulm Ther. 2018:4:171-83.

21. Donohue JF. Minimal clinically important differences in COPD lung function COPD. 2005:2:111-24.

22. D'Urzo AD, Kardos P, Wiseman R. Practical considerations when prescribing a long-acting muscarinic antagonist for patients with COPD. Int J Chron Obstruct Pulmon Dis. 2018:13:1089-104.

23. Martinez FJ, Rabe KF, Lipworth BJ, Arora S, Jenkins M, Maes A, et al. Glycopyrrolate/formoterol fumarate metered dose inhaler (GFF MDI) improves lung function in GOLD category a patients with COPD: pooled data from the phase III PINNACLE studies. Am J Respir Crit Care Med. 2019; 199(Suppl 1):A3345.

24. Punekar YS, Sharma S, Pahwa A, Takyar J, Naya I, Jones PW. Rescue medication use as a patient-reported outcome in COPD: a systematic review and regression analysis. Respir Res. 2017;18:86.

25. Oba Y, Sarva ST, Dias S. Efficacy and safety of long-acting beta-agonist/long acting muscarinic antagonist combinations in COPD: a network metaanalysis. Thorax. 2016;71:15-25.

26. Rodrigo GJ, Price D, Anzueto A, Singh D, Altman P, Bader G, et al. LABA LAMA combinations versus LAMA monotherapy or LABA/ICS in COPD: a 
systematic review and meta-analysis. Int J Chron Obstruct Pulmon Dis. 2017; 12:907-22.

27. Buhl R, de la Hoz A, Voss F, Singh D, Ferguson GT. Efficacy of tiotropium/ olodaterol compared with tiotropium in patients naivve to LAMA, LABA and ICS: pooled analysis of four clinical trials. Am J Respir Crit Care Med. 2019; 199(Suppl 1):A7098.

28. Ferguson GT, Flezar M, Korn S, Korducki L, Gronke L, Abrahams R, et al. Efficacy of tiotropium + olodaterol in patients with chronic obstructive pulmonary disease by initial disease severity and treatment intensity: a post hoc analysis. Adv Ther. 2015;32:523-36.

29. Vestbo J, Edwards LD, Scanlon PD, Yates JC, Agusti A, Bakke P, et al. Changes in forced expiratory volume in 1 second over time in COPD. N Engl J Med. 2011;365:1184-92.

30. Decramer M, Celli B, Kesten S, Lystig T, Mehra S, Tashkin DP, et al. Effect of tiotropium on outcomes in patients with moderate chronic obstructive pulmonary disease (UPLIFT): a prespecified subgroup analysis of a randomised controlled trial. Lancet. 2009;374:1171-8.

31. Celli BR, Thomas NE, Anderson JA, Ferguson GT, Jenkins CR, Jones PW, et al. Effect of pharmacotherapy on rate of decline of lung function in chronic obstructive pulmonary disease: results from the TORCH study. Am J Respir Crit Care Med. 2008;178:332-8.

32. Bridevaux PO, Gerbase MW, Probst-Hensch NM, Schindler C, Gaspoz JM, Rochat T. Long-term decline in lung function, utilisation of care and quality of life in modified GOLD stage 1 COPD. Thorax. 2008;63:768-74.

33. Tantucci C, Modina D. Lung function decline in COPD. Int J Chron Obstruct Pulmon Dis. 2012;7:95-9.

34. Battisti WP, Wager E, Baltzer L, Bridges D, Cairns A, Carswell Cl, et al. Good publication practice for communicating company-sponsored medical research: GPP3. Ann Intern Med. 2015;163:461-4.

\section{Publisher's Note}

Springer Nature remains neutral with regard to jurisdictional claims in published maps and institutional affiliations.

Ready to submit your research? Choose BMC and benefit from:

- fast, convenient online submission

- thorough peer review by experienced researchers in your field

- rapid publication on acceptance

- support for research data, including large and complex data types

- gold Open Access which fosters wider collaboration and increased citations

- maximum visibility for your research: over $100 \mathrm{M}$ website views per year

At $\mathrm{BMC}$, research is always in progress.

Learn more biomedcentral.com/submissions 